This information is current as of April 26, 2023.

Diagnostic Accuracy of T1-Weighted Dynamic Contrast-EnhancedMRI and DWI-ADC for Differentiation of Glioblastoma and Primary CNS Lymphoma

X. Lin, M. Lee, O. Buck, K.M. Woo, Z. Zhang, V. Hatzoglou, A. Omuro, J. Arevalo-Perez, A.A. Thomas, J. Huse, K. Peck, A.I. Holodny and R.J. Young

AJNR Am J Neuroradiol 2017, 38 (3) 485-491

doi: https://doi.org/10.3174/ajnr.A5023

http://www.ajnr.org/content/38/3/485 


\title{
Diagnostic Accuracy of T1-Weighted Dynamic Contrast-Enhanced-MRI and DWI-ADC for Differentiation of Glioblastoma and Primary CNS Lymphoma
}

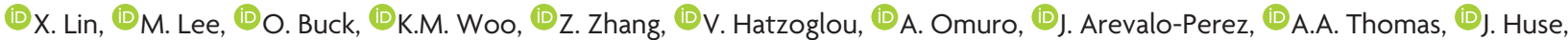

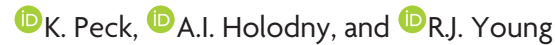

\begin{abstract}
BACKGROUND AND PURPOSE: Glioblastoma and primary CNS lymphoma dictate different neurosurgical strategies; it is critical to distinguish them preoperatively. However, current imaging modalities do not effectively differentiate them. We aimed to examine the use of DWI and TI-weighted dynamic contrast-enhanced-MR imaging as potential discriminative tools.
\end{abstract}

MATERIALS AND METHODS: We retrospectively reviewed 18 patients with primary CNS lymphoma and 36 matched patients with glioblastoma with pretreatment DWI and dynamic contrast-enhanced-MR imaging. VOls were drawn around the tumor on contrastenhanced TIWI and FLAIR images; these images were transferred onto coregistered ADC maps to obtain the ADC and onto dynamic contrast-enhanced perfusion maps to obtain the plasma volume and permeability transfer constant. Histogram analysis was performed to determine the mean and relative $A D C_{\text {mean }}$ and relative 90th percentile values for plasma volume and the permeability transfer constant. Nonparametric tests were used to assess differences, and receiver operating characteristic analysis was performed for optimal threshold calculations.

RESULTS: The enhancing component of primary CNS lymphoma was found to have significantly lower $\operatorname{ADC}_{\text {mean }}\left(1.1 \times 10^{-3}\right.$ versus $1.4 \times$ $\left.10^{-3} ; P<.001\right)$ and relative $A D C_{\text {mean }}(1.5$ versus $1.9 ; P<.001)$ and relative 90 th percentile values for plasma volume $(3.7$ versus $5.0 ; P<.05)$ than the enhancing component of glioblastoma, but not significantly different relative 90th percentile values for the permeability transfer constant (5.4 versus $4.4 ; P=.83$ ). The nonenhancing portions of glioblastoma and primary CNS lymphoma did not differ in these parameters. On the basis of receiver operating characteristic analysis, mean ADC provided the best threshold (area under the curve $=0.83$ ) to distinguish primary CNS lymphoma from glioblastoma, which was not improved with normalized ADC or the addition of perfusion parameters.

CONCLUSIONS: ADC was superior to dynamic contrast-enhanced-MR imaging perfusion, alone or in combination, in differentiating primary CNS lymphoma from glioblastoma.

ABBREVIATIONS: $\mathrm{AUC}=$ area under the curve; $\mathrm{DCE}=$ dynamic contrast-enhanced; $-{ }^{-5} \%$ tile $=5$ th percentile; $\mathrm{GBM}=$ glioblastoma; $K^{\text {trans }}=$ permeability transfer constant; MGMT = O(6)-methylguanin-DNA-methyltransferase; ${ }_{90 \%}$ tile $=90$ th percentile; $\mathrm{PCNSL}=$ primary CNS lymphoma; $r$ - = relative or normalized; Ve $=$ extravascular extracellular volume; $\mathrm{Vp}=$ blood plasma volume

$\mathbf{T}$ he standard of care for glioblastoma (GBM) dictates maximum safe resection. ${ }^{1}$ In contrast, efforts at resection in pri-

Received July 22, 2016; accepted after revision October 7.

From the Departments of Neurology (X.L., A.O., A.A.T.), Radiology (M.L., O.B., V.H., J.A.-P., A.I.H., R.J.Y.), Epidemiology and Biostatistics (K.M.W., Z.Z.), Pathology (J.H.), Medical Physics (K.P.), and The Brain Tumor Center (V.H., A.O., A.I.H., R.J.Y.), Memorial Sloan Kettering Cancer Center, New York, New York; and Department of Neurology (X.L.), National Neuroscience Institute, Singapore.

$X$. Lin and M. Lee contributed equally to the article as co-first authors.

This work was supported in part by National Institutes of Health/National Cancer Center Support Grant P30 CA008748. M. Lee's research was funded, in part, through the National Institutes of Health Memorial Sloan Kettering Cancer Center Medical Student Summer Fellowship program.

Please address correspondence to Robert J. Young, MD, Neuroradiology Service, Department of Radiology, Memorial Sloan Kettering Cancer Center, 1275 York Ave, New York, NY 10065; e-mail: youngr@mskcc.org mary CNS lymphoma (PCNSL) are discouraged due to lack of survival benefits and an increase in postoperative deficits. ${ }^{2,3}$ Given the distinct prognostic implications and the differing surgical planning and treatment options for PCNSL and GBM, their preoperative differentiation is important in patients presenting with an enhancing brain tumor. MR imaging features of PCNSL and GBM are highly variable and overlapping, ${ }^{4,5}$ rendering the differentiation difficult when based solely on conventional MR imaging.

Several studies have suggested the usefulness of diffusionweighted imaging-derived ADC maps in differentiating PCNSL

\footnotetext{
- Indicates open access to non-subscribers at www.ajnr.org

$\checkmark$ Indicates article with supplemental on-line photo.

http://dx.doi.org/10.3174/ajnr.A5023
}

AJNR Am J Neuroradiol 38:485-91 Mar 2017 www.ajnr.org 
from GBM. ${ }^{6,7}$ Due to its higher cellularity compared with GBM, PCNSL has been shown to exhibit lower ADC values. ${ }^{6,7}$ The use of dynamic MR imaging perfusion techniques has also been of growing interest. In pathologic studies, PCNSL and GBM exhibited varying degrees of increased vascular permeability and perfusion. ${ }^{8,9} \mathrm{~T} 2{ }^{\star}$-weighted DSC studies have suggested the discriminative value of cerebral blood volume; however, the results have been inconsistent. ${ }^{10-12}$ More recent studies have suggested the effectiveness of T1-weighted dynamic contrast-enhanced (DCE) perfusion in differentiating PCNSL from GBM. ${ }^{13,14}$ DCE-MR imaging measures fractional blood plasma volume per unit volume of tissue (Vp) and time-dependent leakage (permeability transfer constant $\left.\left[K^{\text {trans }}\right]\right)$, which reflect tissue perfusion and leakiness, respectively. ${ }^{15,16}$ Compared with DSC, DCE perfusion has the advantages of higher spatial resolution, better quantification of microvascular leakiness and perfusion, and increased resistance to susceptibility artifacts. ${ }^{16,17}$

In this study, we aimed to examine the use of DCE-MR imaging and DWI-ADC as potential discriminative tools and to define cutoff (threshold) values for DWI-ADC and DCE perfusion parameters that would be sensitive and specific for PCNSL. We hypothesized that PCNSL would have greater diffusion restriction, while GBM would have greater leakiness and perfusion.

\section{MATERIALS AND METHODS Patient Selection}

This study is an institutional review board-approved retrospective single-institution study performed under a waiver of informed consent. All Health Insurance Portability and Accountability Act regulations were followed. We queried institutional and departmental data bases for all patients with histologically confirmed newly diagnosed PCNSL between January 2011 and December 2014 who had pretreated DWI- and DCE-MR imaging scans available for analysis. As part of our hospital routine practice, all histology was verified by 1 of 2 neuropathologists, both of whom had $>8$ years of experience in neuropathology. We excluded patients under the following conditions: 1) systemic lymphoma, 2) nonparenchymal PCNSL, 3) having undergone chemotherapy before PCNSL diagnosis, and 4) a known history of testing positive for human immunodeficiency virus. A GBM cohort, matched for age and sex, was selected from an institutional data base of newly diagnosed patients with GBM who had histologic confirmation and preoperative DWI and DCE-MR imaging.

Patient charts were reviewed for demographic characteristics, functional status at initial tumor diagnosis, and clinical outcome data. For patients with PCNSL, we collected serum lactate dehydrogenase results obtained within 1 month of tumor diagnosis; for patients with GBM, we collected the available tumor molecular profile, including $O(6)$-methylguanin-DNA-methyltransferase (MGMT) methylation, isocitrate dehydrogenase (IDH) mutation, and epidermal growth factor receptor (EGFR) mutation status.

\section{MR Imaging}

MR imaging sequences were acquired with a 1.5 or 3T MR imaging scanner (Signa Excite, HDx, and Discovery 750; GE Health- care, Milwaukee, Wisconsin) and a standard 8-channel head coil. Gadopentetate dimeglumine (Magnevist; Bayer HealthCare Pharmaceuticals, Wayne, New Jersey) was injected via a venous catheter $(18-21 \mathrm{ga})$ at doses based on patient body weight $(0.2$ $\mathrm{mL} / \mathrm{kg}$ body weight; maximum, $20 \mathrm{~mL}$ ) at $2-3 \mathrm{~mL} / \mathrm{s}$. DWI was acquired in the transverse plane by using a spin-echo, echo-planar imaging sequence with the following parameters: TR/TE $=8000$ / $104.2 \mathrm{~ms}$; diffusion gradient encoding in 3 orthogonal directions; $b=1000 \mathrm{~s} / \mathrm{mm}^{2} ; \mathrm{FOV}=240 \mathrm{~mm} ;$ matrix size $=128 \times 128$ pixels; section thickness $=5 \mathrm{~mm}$; section gap $=1 \mathrm{~mm}$; and number of average $=2$. ADC values were calculated with the following parameters: $\mathrm{ADC}=\left[\ln \left(S / S_{0}\right)\right] / b$, where $S$ is the signal intensity of the ROI obtained through 3 orthogonally oriented DWIs or diffusion trace images, $S_{0}$ is the signal intensity of the ROI acquired through reference T2-weighted images, and $b$ is the gradient $b$ factor with a value of $1000 \mathrm{~s} / \mathrm{mm}^{2}$. ADC maps were calculated on a pixel-by-pixel basis.

DCE-MR imaging of the brain was acquired after DWI scans as part of a standard clinical protocol with an axial 3D T1WI echo-spoiled gradient echo sequence $(\mathrm{TR}=4-5 \mathrm{~ms}$; $\mathrm{TE}=1-2$ $\mathrm{ms}$; section thickness $=5 \mathrm{~mm}$; flip angle $=25^{\circ} ; \mathrm{FOV}=24 \mathrm{~cm}$; matrix $=256 \times 128$; temporal resolution $=5-6$ seconds; number of sections $=10-15$; and total time $=3.3-4$ minutes). Ten phases were acquired preinjection followed by a 30-phase dynamic injection imaging and a $40-\mathrm{mL}$ saline flush. Matching contrastenhanced T1-weighted $(\mathrm{TR} / \mathrm{TE}=600 / 8 \mathrm{~ms}$; thickness $=5$ $\mathrm{mm}$ ) images were also obtained, along with standard sequences including T2-weighted images, FLAIR images, and susceptibility-weighted images. T1 mapping provides a method to calculate the $\mathrm{T} 1$ value of each voxel during the noncontrast phase and has been shown not to significantly alter DCE quantification. ${ }^{18,19}$ Hence, we do not perform T1 mapping for DCE correction at our institution, and it was not available for image processing in this study.

\section{Image Postprocessing and Analysis}

ADC maps, DCE-MR imaging perfusion raw data, contrast-enhanced T1WI, and FLAIR images were transferred to an off-line workstation.

\section{Postprocessing}

DCE-MR imaging perfusion data were processed with FDA-approved commercial software (nordicICE; NordicNeuroLab, Bergen, Norway). The signal-to-noise ratio and arterial input function were optimized individually for each patient. For the arterial input function, an appropriate artery was semiautomatically selected to characterize the input function curve and concentrationtime curve. ${ }^{20}$ The linear assumption between change in signal intensity and gadolinium concentration was made to convert the signal intensity curve to a concentration-time curve. Curves showing an optimal relationship between arterial input function and the concentration-time curve were selected. We used the perfusion analysis method based on the 2-compartment pharmacokinetic model proposed by Tofts et $\mathrm{al}^{20}$ to calculate pharmacokinetic parameters, including $\mathrm{Vp}$ and $K^{\text {trans }}$ and to display the results as parametric maps. 
Table 1: Patient clinical data

\begin{tabular}{|c|c|c|}
\hline Characteristics & GBM & PCNSL \\
\hline No. of patients & 36 & 18 \\
\hline Sex & 22 men, 14 women & 11 men, 7 women \\
\hline Mean age (range) at diagnosis (yr) & $68.6(46-88)$ & $68.7(47-84)$ \\
\hline Tumor type & Glioblastoma multiforme & Diffuse large B-cell lymphoma \\
\hline Median KPS (range) & $90(60-100)$ & $70(50-90)$ \\
\hline LDH (U/L) (median) (range) & & $203(117-334)$ \\
\hline MGMT (No.) & Methylated (10) & \\
\hline & Unmethylated (19) & \\
\hline & Not available (7) & \\
\hline IDH (No.) & Mutated (1) & \\
\hline & Wild-type (30) & \\
\hline & Not available (5) & \\
\hline \multirow[t]{3}{*}{ EGFR amplification/mutation (No.) } & Positive (22) & \\
\hline & Negative (8) & \\
\hline & Not available (6) & \\
\hline
\end{tabular}

Note:-KPS indicates Karnofsky performance status; LDH, lactate dehydrogenase.

Table 2: Imaging results

\begin{tabular}{|c|c|c|c|c|}
\hline $\begin{array}{l}\text { Imaging Parameter } \\
\text { at Enhancing } \\
\text { Tumor (median) }\end{array}$ & $\begin{array}{l}\text { PCNSL } \\
(n=12)\end{array}$ & $\begin{array}{c}\text { GBM } \\
(n=24)\end{array}$ & $\begin{array}{c}P \\
\text { Value }\end{array}$ & AUC \\
\hline $\mathrm{ADC}_{\text {mean }}\left(\mathrm{mm}^{2} / \mathrm{s}\right)$ & $1.1 \times 10^{-3}$ & $1.4 \times 10^{-3}$ & $<.001$ & 0.826 \\
\hline $\mathrm{rADC}_{\text {mean }}$ & 1.5 & 1.9 & $<.001$ & 0.773 \\
\hline $\mathrm{rADC}_{5 \% \text { tile }}$ & 1.1 & 1.1 & .99 & - \\
\hline rVp $90 \%$ tile & 3.7 & 5.0 & .006 & 0.728 \\
\hline$r K^{\text {trans }} 90 \%$ tile & 5.4 & 4.4 & .83 & - \\
\hline
\end{tabular}

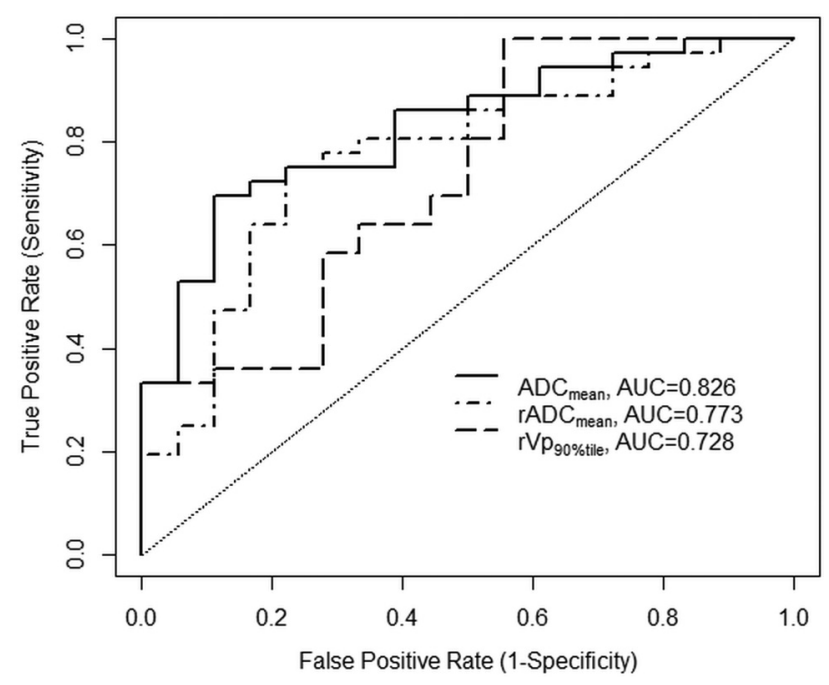

FIG 1. Area under the curve for apparent diffusion coefficient and blood plasma volume. Area under the curve for $\mathrm{ADC}_{\text {mean }}, \mathrm{rADC}_{\text {mean }}$, and $r V p_{90 \% \text { tile }}$ demonstrating the highest $A U C$ value for $A D C_{\text {mean }}$. There are no statistically significantly differences among the 3 AUCs.

\section{Image Analysis}

Two experienced operators ( 1 radiology fellow with 3 years and 1 medical student with 1 year of experience) manually outlined a VOI around the enhancing lesion on contrast-enhanced T1WI and the peritumoral nonenhancing lesion on FLAIR images; the 2 operated independently. The VOI was constructed by summing ROIs drawn around the lesion on all axial sections by the 2 operators, and the final VOI was approved by a board-certified neuroradiologist with 10 years of experience in MR imaging and functional imaging. VOIs were transferred to the ADC, $\mathrm{Vp}$, and $K^{\text {trans }}$ parametric maps, and the corresponding measurements were re- corded for the all enhancing and nonenhancing lesions. Minimum values of zero pixels were removed. To reduce variability related to scanner heterogeneity, contrast, and patient physiology (eg, cardiac output), we normalized all parameters to normal brain by placing ROIs (standardized area of $40-60 \mathrm{~mm}^{2}$ ) in the normal-appearing white matter of the contralateral hemisphere at the midlevel of the tumor. ${ }^{21-23}$ The ROI was placed on the contrast-enhanced T1weighted images and then transferred to the VP and $K^{\text {trans }}$ maps and adjusted, if necessary, to avoid potential outlier areas that may harbor subtle microvascular leakage. The ADC, $\mathrm{Vp}$, and $K^{\text {trans }}$ measurements were binned, and histogram analysis was performed to determine the mean and 90th percentile normalized values for $\mathrm{Vp}\left(\mathrm{rVp}_{\text {mean }} ; \mathrm{rVp}_{90 \% \text { tile }}\right)$ and $K^{\text {trans }}$, and the mean and fifth percentile normalized values for $\mathrm{ADC}$ ( $\mathrm{rADC}_{\text {mean }}$, $\left.\mathrm{rADC}_{5 \% \text { tile }}\right)$. The 90 th percentile for $\mathrm{Vp}$ and $K^{\text {trans }}$ characterizes the portion of the tumor with the highest perfusion, while the fifth percentile for ADC determines the portion of the tumor with the greatest degree of restricted diffusion. To facilitate comparisons with prior studies, we also recorded absolute (non-normalized) $\mathrm{ADC}_{\text {mean }}$ and $\mathrm{ADC}_{5 \% \text { tile }}$ values.

\section{Statistical Analysis}

Wilcoxon rank sum tests were conducted to assess differences between GBM and PCNSL groups for normalized ADC, $K^{\text {trans }}$, and Vp parameters. Measurements from enhancing and nonenhancing lesions were analyzed separately. The significance of $P$ values was adjusted by using the false discovery rate approach. Receiver operating characteristic analysis was performed for the parameters with statistically significant differences, and the area under the curve (AUC) was computed. ${ }^{24}$ Optimal thresholds were estimated with consideration for sensitivity and specificity. Overall survival was estimated by using the Kaplan-Meier method, starting from the date of tumor diagnosis until death. Patients who did not die during the study period were censored at the date of last available follow-up. Statistical analysis was performed by using R statistical and computing software (http:// www.r-project.org/), including the "ROCR" and "survival" packages. We retrospectively reviewed all patients with pretreated primary CNS lymphoma who underwent evaluation with DCE-MR imaging at our center and selected a GBM cohort matched for age and sex; hence, a sample size calculation was not performed for this study.

\section{RESULTS}

\section{Patient Population}

We identified 18 patients with PCNSL (11 men; mean age, 68.7 years) and 36 matched patients with GBM (22 men; mean age, 68.6 years) who met all the inclusion criteria. The patient-selection process and clinical data are summarized in On-line Fig 1 and Table 1, respectively. 


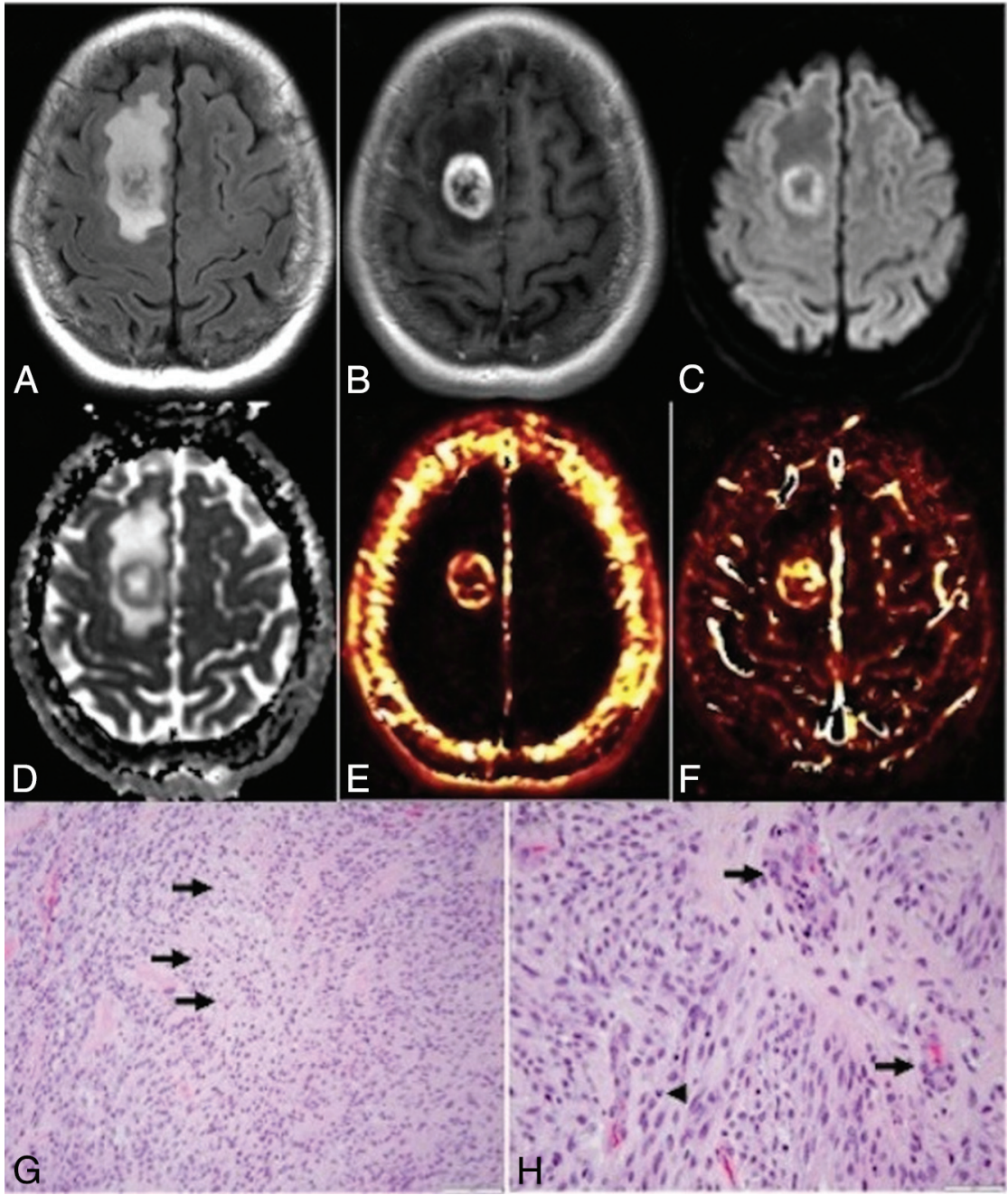

FIG 2. Glioblastoma. Axial FLAIR (A), contrast-enhanced T7-weighted (B), diffusion-weighted (C), ADC $(D)$, permeability transfer constant $(E)$, and plasma volume $(F)$ images reveal a heterogeneously enhancing tumor in the right frontal lobe with peripheral diffusion restriction (low on $A D C, D$ ), increased leakiness $(E)$, and increased perfusion $(F)$. These findings suggest areas of cellular tumor with marked neovascularity and areas of necrosis. Micrographs $(G$ and $H)$ show high glial neoplasm with necrosis $(G$, arrows), microvascular proliferations ( $H$, arrows), and mitotic activity ( $H$, arrowhead), consistent with a diagnosis of glioblastoma. Magnification $\times 20(G)$ and $\times 40(H)$.

\section{$A D C$}

For the enhancing lesions, the median rADC $_{\text {mean }}$ was lower for PCNSL than for GBM (PCNSL versus GBM, 1.5 versus $1.9 ; P<.001)$. On the basis of receiver operating characteristic analysis, a $\mathrm{rADC}_{\text {mean }}$ threshold of $<1.7$ indicated PCNSL with a specificity of $78 \%$ and sensitivity of $75 \%$. For the nonenhancing lesions, the $\mathrm{rADC}_{\text {mean }}$ was not significantly different $(P=$ .21). When tested without normalization to a ratio, the median $\mathrm{ADC}_{\text {mean }}$ of the enhancing lesions was also lower in PCNSL than in GBM $\left(1.1 \times 10^{-3}\right.$ $\mathrm{mm}^{2} / \mathrm{s}$ versus $1.4 \times 10^{-3} \mathrm{~mm}^{2} / \mathrm{s} ; P<$ $.001)$; an $\mathrm{ADC}_{\text {mean }}$ threshold of $<1.3 \times 10^{-3} \mathrm{~mm}^{2} / \mathrm{s}$ indicated PCNSL with a specificity of $89 \%$ and sensitivity of $69 \%$. There was no significant difference in the AUCs for $\mathrm{ADC}_{\text {mean }}$ and $\mathrm{rADC}_{\text {mean }}(P=.88)$.

\section{DCE-MR Imaging}

For the enhancing lesions, the median $\mathrm{rVp}_{90 \% \text { tile }}$ was lower for PCNSL than for GBM (3.7 versus 5.0; $P=.006$ ), while the median $K^{\text {trans }}{ }_{90 \% \text { tile }}$ was not significantly different $(P=.83)$ between the two. For the nonenhancing lesions, neither $\mathrm{rVp}_{90 \% \text { tile }}$ nor the $\mathrm{r} K^{\text {trans }}{ }_{90 \% \text { tile }}$ was significantly different $(P \geq .16)$. If one optimized specificity and sensitivity, a $\mathrm{rVp}_{90 \% \text { tile }}$ threshold of $<4.6$ indicated PCNSL with a specificity of $72 \%$ and sensitivity of $58 \%$. The AUC for $\mathrm{rVp}_{90 \% \text { tile }}$ was not significantly different from that for $\mathrm{ADC}_{\text {mean }}(P=.87)$ or $\mathrm{rADC}_{\text {mean }}(P=.66)$.
In the PCNSL and GBM cohorts, the median Karnofsky performance status at tumor diagnosis was 70 and 90, respectively. At last follow-up, all except 1 (94.4\%) patient with PCNSL were alive, with a median follow-up of 22.1 months. One patient died 21.3 months after diagnosis, and the 12month overall survival in the PCNSL cohort was $100 \%$. The 12-month overall survival in the GBM cohort was $48.5 \%$ (95\% CI, 29.6\%-64.9\%).

In the PCNSL cohort, the mean serum lactate dehydrogenase was 203.1 U/L (range, 117.0-334.0 U/L). Among GBM samples with available MGMT methylation $(n=29)$, IDH mutation $(n=31)$, and EGFR mutation $(n=30)$ status, $10(34.5 \%)$ were MGMT methylated, 1 (3.2\%) was IDH mutated, and $22(73.3 \%)$ were EGFR mutant.

\section{Imaging Findings}

The imaging results are summarized in Table 2 and Fig 1, and representative PCNSL and GBM cases are shown in Figs 2 and 3.

\section{Combining ADC and DCE-MR Imaging}

If one combined $\mathrm{ADC}_{\text {mean }}$ and $\mathrm{rVp}_{90 \% \text { tile }}$ at the enhancing lesion, a binary threshold of $\mathrm{ADC}_{\text {mean }}<1.3 \times 10^{-3} \mathrm{~mm}^{2} / \mathrm{s}$ and $\mathrm{rVp}_{90 \% \text { tile }}<4.6$ predicted PCNSL with a specificity of $61 \%$ and a sensitivity of $83 \%$. Conversely, a binary threshold of $\mathrm{ADC}_{\text {mean }} \geq$ $1.3 \times 10^{-3} \mathrm{~mm}^{2} / \mathrm{s}$ and $\mathrm{rVp}_{90 \% \text { tile }} \geq 4.6$ predicted GBM with a specificity of $94 \%$ and sensitivity of $47 \%$.

\section{DISCUSSION}

We retrospectively examined the use of ADC and DCE in differentiating pretreated PCNSL from GBM. We found that $\mathrm{ADC}_{\text {mean }}$, $\mathrm{rADC}_{\text {mean }}$, and $\mathrm{rVp}_{90 \% \text { tile }}$, but not $r K^{\text {trans }}$ in the enhancing regions, distinguished PCNSL and GBM (Table 2). An $\mathrm{ADC}_{\text {mean }}$ threshold of $1.3 \times 10^{-3} \mathrm{~mm}^{2} / \mathrm{s}$ discriminated PCNSL and GBM with the best specificity and sensitivity; a binary threshold that combined $\mathrm{ADC}_{\text {mean }}$ and $\mathrm{rVp}_{90 \% \text { tile }}$ values was helpful for predicting GBM but less so for PCNSL. 


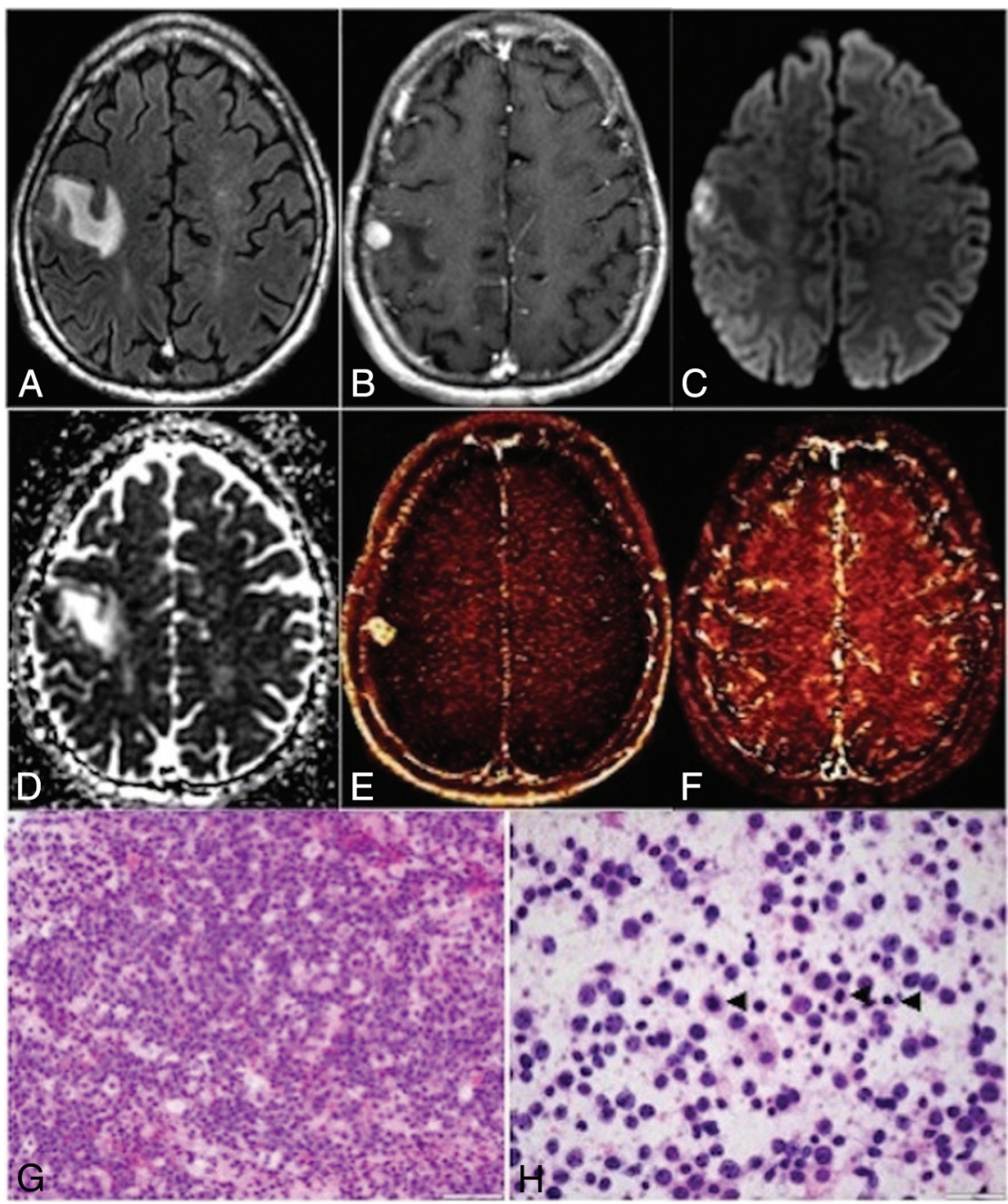

FIG 3. Primary CNS lymphoma. Axial FLAIR $(A)$, contrast-enhanced TT-weighted $(B)$, diffusionweighted $(C)$, $A D C(D)$, permeability transfer constant $(E)$, and plasma volume $(F)$ images show an enhancing tumor in the right frontal lobe with diffusion restriction $(D)$, increased leakiness (high on $K^{\text {trans }}, E$ ), and only slightly increased perfusion (slightly high on $\mathrm{Vp}, F$ ). These findings indicate cellular tumor without marked neovascularity, typical for primary CNS lymphoma. Micrographs ( $G$ and $H$ ) show high-grade lymphoid proliferation with obvious mitotic activity in the cytology preparation $(H$,arrowheads). Magnification $\times 40(G$ and $H)$.

Our study findings are consistent with previous studies demonstrating significantly lower ADC in PCNSL than in GBM. ${ }^{6,7,25,26}$ In a subset of these studies, DWI results were correlated with histologic information and showed a clear inverse relationship between ADC and tumor cellularity, 6,7,26 suggesting that untreated PCNSL has higher tumor density than untreated GBM. In contrast to these studies, we also studied relative normalized ADC values but did not find any improved discriminative performance with $\mathrm{rADC}_{\text {mean }}$ over absolute $\mathrm{ADC}_{\text {mean. }}$. We therefore advocate the use of $\mathrm{ADC}_{\text {mean }}$, which is a simpler and more direct measurement than $\mathrm{rADC}_{\text {mean }}$, to distinguish PCNSL and GBM.

Our study also examined the use of the DCE-MR imaging technique and showed that $\mathrm{rVp}$ was able to distinguish PCNSL from GBM. Vp was not part of the original Tofts model and was introduced later in the modified Tofts model to account for intravascular tracer. ${ }^{15}$ In gliomas, Vp has been shown to differentiate tumor grade. ${ }^{27}$ However, Vp has not be shown to be useful in differentiating PCNSL from GBM. $^{14}$ Our study, to the best of our knowledge, is the first to demonstrate the discriminating value of $\mathrm{rVp}_{90 \% \text { tile; }}$ this positive finding may be related to our choice of a normalized parameter to reduce interscanner, interrater, and interpatient variability.

$K^{\text {trans }}$ is the other commonly measured DCE-MR imaging parameter. It measures the degree of increase in $\mathrm{T} 1$ due to contrast accumulation in tissue and can be affected by multiple factors such as blood flow and capillary wall surface area. In general, it is used to represent leakiness due to capillary permeability and blood-brain barrier disruption. ${ }^{16}$ A study by Kickingereder et al ${ }^{13}$ showed that PCNSL had significantly higher $K^{\text {trans }}$ than GBM and further correlated these radiologic findings with histologic demonstration of destroyed vessel architecture in the 11 PCNSLs and intact vascular integrity in the 60 GBMs. With CT perfusion imaging, $K^{\text {trans }}$ was also shown to be significantly higher in PCNSL than in GBM in one study ${ }^{28}$ but not in a subsequent study ${ }^{29}$; this latter negative study was attributed to the use of the Patlak model, which fails to account for backflow of contrast agent from the extravascular extracellular space to the blood plasma, compromising $K^{\text {trans }}$ measurement. Our study also showed a trend for higher $K^{\text {trans }}$ in PCNSL than in GBM, but the difference was not statistically significant.

Our results indicated that $\mathrm{rVp}$ is not superior to ADC for identifying PCNSL, and a combined model including $\mathrm{rVp}_{90 \% \text { tile }}$ and $\mathrm{ADC}_{\text {mean }}$ is not superior to either technique alone. Perfusion MR imaging has been suggested as a valuable part of the imaging strategy for the differential diagnosis of undiagnosed brain masses. ${ }^{30,31}$ In addition, perfusion MR imaging has demonstrated additional value in gliomas with correlations to glioma grade, EGFR gene amplification and vIII status, MGMT methylation status, time-to-progression, and overall survival. ${ }^{21,32-37}$ Therefore, while not superior for differential diagnosis purposes, DCE-MR imaging may be helpful to support the presumptive diagnosis of PCNSL when marked hyperperfusion is absent, and it can be considered to provide important prognostic data about tumor vascularity and leakiness independent of data about tumor cellularity.

Unlike previous studies that examined imaging parameters solely at contrast-enhancing regions, we evaluated imaging parameters at both enhancing and nonenhancing regions but failed to show any added discriminative value. This outcome suggests 
that increases in tumor cellularity, microvascular permeability, and vascular proliferation are less marked in nonenhancing areas of different brain tumors compared with contrast-enhancing regions. Although nonenhancing regions in glioblastomas are known to include a combination of tumor and peritumoral edema, ${ }^{38}$ quantification of tumor-related imaging characteristics is dependent on the relative abundance of tumor cells and may be diluted by the amount of edema. ${ }^{26}$

Our study has several potential limitations. First, we did not examine all DCE-MR imaging parameters, including extravascular extracellular volume (Ve), which was shown in 1 study to differentiate PCNSL from other brain tumors. ${ }^{14}$ This study by Abe et $\mathrm{al}^{14}$ used a DCE-MR imaging sequence with a shorterthan-standard acquisition time, however, which potentially overestimates $K^{\text {trans }}$ and underestimates $\mathrm{Vp}$ and $\mathrm{Ve},{ }^{39}$ thereby limiting the generalizability of the results. In addition, the physiologic meaning of Ve remains elusive, with conflicting studies demonstrating its correlation with tumor cellularity. ${ }^{7,26,40}$ The use of Ve is further refuted by an earlier study that failed to show a significant difference in Ve between PCNSL and GBM. ${ }^{13}$ We did not evaluate Ve in our study and, instead, chose ADC as a more reliable and widely applied marker of tumor cellularity. ${ }^{7,26}$ Second, we did not evaluate the performance of other conventional MR imaging parameters such as the presence of necrosis and rim enhancement. Previous studies have shown that PCNSL has variable degrees of T1 and T2 intensities, extent of necrosis, and pattern of contrast enhancement-suggesting that these features are unreliable in distinguishing lymphoma from other CNS lesions. ${ }^{41,42}$ Consequently, in 1 prior study, the use of rim enhancement and central necrosis resulted in misclassification of 3 (17.6\%) of 17 PCNSLs and malignant gliomas. ${ }^{30}$ Given the statistical limitations of our relatively small sample size of patients with PCNSL who underwent DCE-MR imaging, we chose to focus our study on examining ADC, rather than all the other conventional MR imaging parameters. Our small sample size also limited our ability to use cross-validation to assess the operating characteristics and validate the sensitivities and specificities of the cutoff values determined in our study. Third, we did not account for the presence of microbleed, which may confound ADC and DCE-MR imaging results. However, the additional step of eliminating microbleed by using an additional SWI sequence may pose impractical constraints and limit the applicability of our study. Fourth, due to the lack of the routine use of MR spectroscopy in this retrospective study, we were unable to evaluate the utility of MR spectroscopy, which has been shown to distinguish PCNSL from GBM in 1 study with a specificity exceeding $90 \% .{ }^{43}$ The added value of MR spectroscopy in discriminating the diagnoses should be incorporated in future prospective studies. Fifth, the manual drawing and transfer of VOIs to parametric maps could have introduced variability. We sought to reduce the variability by having all VOIs drawn by operators who had at least 1 year of experience and reviewed by an experienced board-certified neuroradiologist and by exploiting the histogram function to interrogate only the most abnormal parts of the tumor.

\section{CONCLUSIONS}

Pretreatment differentiation of PCNSL and GBM is challenging. Our study suggests that DCE-MR imaging is helpful in identifying PCNSL, though rVp did not outperform ADC and a combined model did not outperform either metric alone. Further prospective studies are needed to confirm these findings.

\section{ACKNOWLEDGMENTS}

We thank Ms Joanne Chin for her editorial work in the preparation of this manuscript.

Disclosures: Robert J. Young-UNRELATED: Consultancy: Agios Glioma Advisory Board, Comments: honorarium; Grants/Grants Pending: Dana Foundation. * *Money paid to the institution

\section{REFERENCES}

1. Marko NF, Weil RJ, Schroeder JL, et al. Extent of resection of glioblastoma revisited: personalized survival modeling facilitates more accurate survival prediction and supports a maximum-safe-resection approach to surgery. J Clin Oncol 2014;32:774-82 CrossRef Medline

2. Bataille B, Delwail V, Menet E, et al. Primary intracerebral malignant lymphoma: report of 248 cases. J Neurosurg 2000;92:261-66 CrossRef Medline

3. DeAngelis LM, Yahalom J, Heinemann MH, et al. Primary CNS lymphoma: combined treatment with chemotherapy and radiotherapy. Neurology 1990;40:80-86 CrossRef Medline

4. Koeller KK, Smirniotopoulos JG, Jones RV. Primary central nervous system lymphoma: radiologic-pathologic correlation. Radiographics 1997;17:1497-526 CrossRef Medline

5. Rees JH, Smirniotopoulos JG, Jones RV, et al. Glioblastoma multiforme: radiologic-pathologic correlation. Radiographics 1996; 16:1413-38; quiz 62-63 Medline

6. Doskaliyev A, Yamasaki F, Ohtaki M, et al. Lymphomas and glioblastomas: differences in the apparent diffusion coefficient evaluated with high b-value diffusion-weighted magnetic resonance imaging at 3T. Eur J Radiol 2012;81:339-44 CrossRef Medline

7. Guo AC, Cummings TJ, Dash RC, et al. Lymphomas and high-grade astrocytomas: comparison of water diffusibility and histologic characteristics. Radiology 2002;224:177-83 CrossRef Medline

8. Molnár PP, O’Neill BP, Scheithauer BW, et al. The blood-brain barrier in primary CNS lymphomas: ultrastructural evidence of endothelial cell death. Neuro Oncol 1999;1:89-100 CrossRef Medline

9. Jain RK, di Tomaso E, Duda DG, et al. Angiogenesis in brain tumours. Nat Rev Neurosci 2007;8:610-22 CrossRef Medline

10. Xing Z, You RX, Li J, et al. Differentiation of primary central nervous system lymphomas from high-grade gliomas by rCBV and percentage of signal intensity recovery derived from dynamic susceptibility-weighted contrast-enhanced perfusion MR imaging. Clin Neuroradiol 2014;24:329-36 CrossRef Medline

11. Toh CH, Wei KC, Chang CN, et al. Differentiation of primary central nervous system lymphomas and glioblastomas: comparisons of diagnostic performance of dynamic susceptibility contrast-enhanced perfusion MR imaging without and with contrast-leakage correction. AJNR Am J Neuroradiol 2013;34:1145-49 CrossRef Medline

12. Kickingereder P, Wiestler B, Sahm F, et al. Primary central nervous system lymphoma and atypical glioblastoma: multiparametric differentiation by using diffusion-, perfusion-, and susceptibilityweighted MR imaging. Radiology 2014;272:843-50 CrossRef Medline

13. Kickingereder P, Sahm F, Wiestler B, et al. Evaluation of microvascular permeability with dynamic contrast-enhanced MRI for the differentiation of primary CNS lymphoma and glioblastoma: radiologic-pathologic correlation. AJNR Am J Neuroradiol 2014;35: 1503-08 CrossRef Medline

14. Abe T, Mizobuchi Y, Nakajima K, et al. Diagnosis of brain tumors 
using dynamic contrast-enhanced perfusion imaging with a short acquisition time. Springerplus 2015;4:88 CrossRef Medline

15. Bergamino M, Bonzano L, Levrero F, et al. A review of technical aspects of T1-weighted dynamic contrast-enhanced magnetic resonance imaging (DCE-MRI) in human brain tumors. Phys Med 2014; 30:635-43 CrossRef Medline

16. Cha S. Update on brain tumor imaging: from anatomy to physiology. AJNR Am J Neuroradiol 2006;27:475-87 Medline

17. Essig M, Shiroishi MS, Nguyen TB, et al. Perfusion MRI: the five most frequently asked technical questions. AJR Am J Roentgenol 2013;200:24-34 CrossRef Medline

18. Haacke EM, Filleti CL, Gattu R, et al. New algorithm for quantifying vascular changes in dynamic contrast-enhanced MRI independent of absolute T1 values. Magn Reson Med 2007;58:463-72 CrossRef Medline

19. Jung SC, Yeom JA, Kim JH, et al. Glioma: application of histogram analysis of pharmacokinetic parameters from T1-weighted dynamic contrast-enhanced MR imaging to tumor grading. AJNR Am J Neuroradiol 2014;35:1103-10 CrossRef Medline

20. Tofts PS, Brix G, Buckley DL, et al. Estimating kinetic parameters from dynamic contrast-enhanced T(1)-weighted MRI of a diffusable tracer: standardized quantities and symbols. J Magn Reson Imaging 1999;10:223-32 Medline

21. Arevalo-Perez J, Thomas AA, Kaley T, et al. T1-weighted dynamic contrast-enhanced MRI as a noninvasive biomarker of epidermal growth factor receptor vIII status. AJNR Am J Neuroradiol 2015;36: 2256-61 CrossRef Medline

22. Thomas AA, Arevalo-Perez J, Kaley T, et al. Dynamic contrast enhanced T1 MRI perfusion differentiates pseudoprogression from recurrent glioblastoma. J Neurooncol 2015;125:183-90 CrossRef Medline

23. Zhang M, Gulotta B, Thomas A, et al. Large-volume low apparent diffusion coefficient lesions predict poor survival in bevacizumab-treated glioblastoma patients. Neuro Oncol 2016;18: 735-43 CrossRef Medline

24. DeLong ER, DeLong DM, Clarke-Pearson DL. Comparing the areas under two or more correlated receiver operating characteristic curves: a nonparametric approach. Biometrics 1988;44: 837-45 CrossRef Medline

25. Yamashita K, Yoshiura T, Hiwatashi A, et al. Differentiating primary CNS lymphoma from glioblastoma multiforme: assessment using arterial spin labeling, diffusion-weighted imaging, and ${ }^{18} \mathrm{~F}$-fluorodeoxyglucose positron emission tomography. Neuroradiology 2013; 55:135-43 CrossRef Medline

26. Kono K, Inoue $\mathrm{Y}$, Nakayama $\mathrm{K}$, et al. The role of diffusion-weighted imaging in patients with brain tumors. AJNR Am J Neuroradiol 2001;22:1081-88 Medline

27. Lüdemann L, Grieger W, Wurm R, et al. Quantitative measurement of leakage volume and permeability in gliomas, meningiomas and brain metastases with dynamic contrast-enhanced MRI. Magn Reson Imaging 2005;23:833-41 CrossRef Medline

28. Warnke PC, Timmer J, Ostertag CB, et al. Capillary physiology and drug delivery in central nervous system lymphomas. Ann Neurol 2005;57:136-39 CrossRef Medline

29. Schramm P, Xyda A, Klotz E, et al. Dynamic CT perfusion imaging of intra-axial brain tumours: differentiation of high-grade gliomas from primary CNS lymphomas. Eur Radiol 2010;20:2482-90 CrossRef Medline

30. Al-Okaili RN, Krejza J, Woo JH, et al. Intraaxial brain masses: MR imaging-based diagnostic strategy-initial experience. Radiology 2007;243:539-50 CrossRef Medline

31. Omuro AM, Leite CC, Mokhtari K, et al. Pitfalls in the diagnosis of brain tumours. Lancet Neurol 2006;5:937-48 CrossRef Medline

32. Arevalo-Perez J, Peck KK, Young RJ, et al. Dynamic contrast-enhanced perfusion MRI and diffusion-weighted imaging in grading of gliomas. J Neuroimaging 2015;25:792-98 CrossRef Medline

33. Gupta A, Young RJ, Shah AD, et al. Pretreatment dynamic susceptibility contrast MRI perfusion in glioblastoma: prediction of EGFR gene amplification. Clin Neuroradiol 2015;25:143-50 CrossRef Medline

34. Jain KK, Sahoo P, Tyagi R, et al. Prospective glioma grading using single-dose dynamic contrast-enhanced perfusion MRI. Clinical Radiol 2015;70:1128-35 CrossRef Medline

35. Ahn SS, Shin NY, Chang JH, et al. Prediction of methylguanine methyltransferase promoter methylation in glioblastoma using dynamic contrast-enhanced magnetic resonance and diffusion tensor imaging. J Neurosurg 2014;121:367-73 CrossRef Medline

36. Choi HS, Kim AH, Ahn SS, et al. Glioma grading capability: comparisons among parameters from dynamic contrast-enhanced MRI and ADC value on DWI. Korean J Radiol 2013;14:487-92 CrossRef Medline

37. Law M, Young RJ, Babb JS, et al. Gliomas: predicting time to progression or survival with cerebral blood volume measurements at dynamic susceptibility-weighted contrast-enhanced perfusion MR imaging. Radiology 2008;247:490-98 CrossRef Medline

38. Wen PY, Macdonald DR, Reardon DA, et al. Updated response assessment criteria for high-grade gliomas: Response Assessment in Neuro-Oncology working group. J Clin Oncol 2010;28:1963-72 CrossRef Medline

39. Larsson C, Kleppesto M, Rasmussen I Jr, et al. Sampling requirements in DCE-MRI based analysis of high grade gliomas: simulations and clinical results. J Magn Reson Imaging 2013;37:818-29 CrossRef Medline

40. Mills SJ, Soh C, Rose CJ, et al. Candidate biomarkers of extravascular extracellular space: a direct comparison of apparent diffusion coefficient and dynamic contrast-enhanced MR imaging-derived measurement of the volume of the extravascular extracellular space in glioblastoma multiforme. AJNR Am J Neuroradiol 2010;31: 549-53 CrossRef Medline

41. Johnson BA, Fram EK, Johnson PC, et al. The variable MR appearance of primary lymphoma of the central nervous system: comparison with histopathologic features. AJNR Am J Neuroradiol 1997;18: 563-72 Medline

42. Slone HW, Blake JJ, Shah R, et al. CT and MRI findings of intracranial lymphoma. AJR Am J Roentgenol 2005;184:1679-85 CrossRef Medline

43. Aburano H, Ueda F, Yoshie Y, et al. Differences between glioblastomas and primary central nervous system lymphomas in $1 \mathrm{H}-$ magnetic resonance spectroscopy. Jpn J Radiol 2015;33:392-403 CrossRef Medline 